\title{
DE VENENOS, ESCUTAS E ASSOMBRAÇÕES: CAMINHOS PARA ETNOGRAFAR O SILÊNCIO
}

\author{
Larissa Nadai ${ }^{1}$ \\ Rafael do Nascimento Cesar ${ }^{2}$ \\ Cilmara Veiga ${ }^{3}$ \\ ${ }^{1}$ Universidade de São Paulo (USP), São Paulo/SP, Brasil \\ ${ }^{2}$ Instituto de Filosofia e Ciências Humanas da Unicamp \\ (IFCH/Unicamp),Campinas/SP, Brasil \\ ${ }^{3}$ Programa de Pós-Graduação em Ciências Sociais, \\ Universidade Estadual de Campinas (PPGCS/Unicamp), Campinas/SP, Brasil
}

A linguagem diz peremptoriamente quando renuncia a dizer a própria coisa.

Maurice Merleau-Ponty

"O resto é silêncio". Com esta frase, o moribundo príncipe Hamlet despedia-se de Horácio e encerrava a mais célebre das tragédias de Shakespeare. Vendo ruir tanto a soberania do reino da Dinamarca quanto os vínculos da família real, ele roga a seu amigo no leito de morte que relate a Fortinbrás, sucessor do trono, os "grandes e pequenos acontecimentos" que culminaram no conhecido desfecho da peça (Shakespeare s/d:260). Munido apenas da palavra, caberia a Horácio reconstituir detalhadamente o que viu e ouviu, e com seu testemunho elaborar uma versão "verdadeira" dos fatos, restaurando assim a honra do príncipe envenenado, bem como a do reino apodrecido. O "resto", tudo aquilo não ungido pelo poder da palavra, ficaria de fora da história e cairia no esquecimento dos homens. O silêncio, para o personagem a antimatéria da fala e da verdade, corresponderia, tragicamente, à impossibilidade de qualquer conhecimento.

Instigado pelo apelo de Hamlet a Horácio, este ensaio procura, ao contrário da obra de Shakespeare, sublinhar o caráter produtivo do ato de silenciar e daquilo que se torna dizível por meio de outros expedientes que não a palavra proferida - olhares, gestos, pausas. Inspirados pelas 
proposições de Michel Foucault (1988), buscamos colocar sob rasura as representações do silêncio como reino do incognoscível, da falta ou ausência de linguagem. Para fazê-lo a contento, propomos a leitura articulada de três obras: Life and Words, de Veena Das (2007); Bearing Witness, de Fiona Ross (2003); e Haunting the Korean Diaspora, de Grace Cho (2008). ${ }^{1}$ Veena Das filia-se diretamente às proposições de Wittgenstein, assim como Fiona Ross, que conduz suas análises inspirada pelos trabalhos da antropóloga indiana. Para ambas as autoras, a linguagem atuaria como um limite ao mundo vivido e um jogo, simultaneamente. Já Cho, por certo inspirada pelas análises freudianas, ancora suas reflexões na tensa e conflitiva relação entre trauma, narração, catarse e processos de elaboração.

Oriundas de searas intelectuais bastante distintas, nossa escolha em uni-las num mesmo ensaio bibliográfico resulta do modo como, no Brasil, essa trinca de autoras vem sendo lida e seus trabalhos relacionados. ${ }^{2}$ Ao dizer isto, intentamos sublinhar o modo como suas pesquisas, ao pensarem temas como violência, políticas de memória e reparação, Estado, guerra e gênero, confrontam tanto a noção de que a violência e a dor são em si mesmas antitéticas à linguagem (Scarry 1985) quanto às prerrogativas do silêncio como domínio do indizível, da repressão e do mutismo. ${ }^{3}$ Nos rastros de tais proposições, cremos ser potente lidar com uma concepção ampliada de linguagem, sensível tanto às maneiras de dizer quanto às de gerir o indizível. Ao escolhermos tal caminho, asseveramos que ele, o silêncio, elevado a um patamar heurístico, também compõe a "série de segmentos descontínuos" que dão corpo aos discursos a um só tempo como "instrumento e efeito do poder, e também obstáculo, escora, ponto de resistência e ponto de partida de uma estratégia oposta" (Foucault 1988:111-112).

\section{Modalidades do silêncio}

Life and Words é uma compilação de onze ensaios alinhavados na relação entre dois eventos históricos críticos - a Partição da Índia, que deu origem aos Estados-nação indiano e paquistanês em 1947, e o assassinato da então primeira-ministra Indira Gandhi em 1984. A etnografia foi animada, de um lado, pelo convívio de Veena Das com famílias urbanas da região do Punjabi deslocadas pelo processo da Partição e, de outro lado, pela assistência a famílias sikhs afetadas pelos massacres ocorridos em virtude do assassinato de Indira Gandhi. Em ambos os casos, a autora procurou narrar as maneiras encontradas por esses sujeitos para "habitar um mundo" destruído e irrestituível à sua forma original (Das 2007:2). 
Atenta às diferentes modalidades por eles empregadas para dar inteligibilidade à violência resultante desses eventos, a autora mostra que muitas famílias lidaram em seus cotidianos com aquilo que "somente poderia ser moldado em um silêncio" (Das 2007:10). A experiência da desagregação do tecido social (a perda de familiares, os raptos, os estupros e os deslocamentos forçados), em vez de admitir narrativas coerentes pelas mulheres que a vivenciaram, constituía, antes, uma espécie de "conhecimento venenoso" [poison knowledge] cuja memória não poderia ser enunciada senão por meio de "slides congelados" (Das 2007:80).

A história de Manjit é disto ilustrativa. Raptada durante a Partição e, tempos depois, resgatada pelo exército indiano, ela foi viver com o irmão de sua mãe (mama), responsável pelo arranjo de seu casamento com um homem muito mais velho e com quem tinha um parentesco muito distante. A história do que teria acontecido a Manjit no intervalo entre o rapto e o resgate não era conhecida e, após o casamento, seu marido foi consumido pelas suspeitas de que ela teria sido violentada por um homem mulçumano. Diante de todas as injúrias proferidas pelo marido e pela sogra - canalizadas também para seu filho mais velho - "Manjit era como pedra", nas palavras de Das (2007:85). Tal paciência em face dessa violência difusa e cotidiana é atravessada pela visão de que o tempo é "um agente que 'trabalha' nas relações" - o tempo como "um carrasco cruel" (Das 2007:86) - sendo tal paciência, portanto, parte da luta travada diariamente quanto ao que ela acreditava ser a verdade sobre sua família e sua história.

A "existência de formas narrativas, simbólicas e sociais" (Das 2007:86) capazes de compreender essa forma de violência tecida nas relações domésticas e familiares contrasta com um outro tipo de violência do qual Manjit foi também vítima: a experiência da Partição. Se no primeiro caso a violência vivida tem "um sentido de pretérito composto, continuamente recomposto" (Das 1999:38), no segundo, trata-se de uma violência súbita e traumática sobre a qual pesa uma "cortina de silêncio" (Das 1999:37) e cuja narrativa (ou não narrativa) opera como slides congelados. Como argumenta a autora, as histórias sobre os acontecimentos da Partição (nunca contadas em primeira pessoa) inserem-se numa narrativa metafórica e fantástica de sacrifícios heroicos feitos por mulheres que se atiraram em poços com a suspeita da chegada de bandos mulçumanos ou foram assassinadas por seus familiares para serem poupadas da desonra do rapto. Outras histórias acionavam a voz anônima do "dizia-se então" ou do "escutavam-se estranhas histórias", permanecendo sem autoria. De caráter hiperbólico e repleto de metáforas, os relatos de Manjit emergem dessa história maior a respeito do rapto, do estupro e da violência perpetrada às mulheres durante a Partição. 
Ela fala em "rios de sangue" e na terra "coberta de mortalhas brancas até o horizonte" (Das 2007:54). Manjit não se recusa a contar sobre a Partição, mas não faz referência às atrocidades e violações que foram testemunhadas ou sofridas por ela naquele contexto.

Em forte conexão com as premissas teórico-analíticas desenhadas por Das, Bearing Witness se debruça sobre as intricadas formas pelas quais a Comissão da Verdade e Reconciliação na África do Sul atuou durante o processo de transição democrática pós-apartheid (1995-1998). Resultado da tese de doutorado de Fiona Ross, o livro tem como objetivo deslindar as complexas formas pelas quais as ideias de sofrimento, justiça, direitos humanos, prestação de contas, história e testemunho foram articuladas na e pela mencionada Comissão a partir do testemunho dado por mulheres cujas vidas foram impactadas pelo regime do apartheid (1948-1994).

Para tanto, a autora deu atenção aos artefatos legislativos, aos documentos e às audiências públicas que instituíram e estruturaram a atuação das Comissões de Verdade e Reconciliação na África do Sul. Além disso, observou também os efeitos causados pelo ato de testemunhar na vida comunitária daqueles que se apresentaram perante tais aparatos de "escuta". Segundo mostra Fiona Ross, mediante a composição e a confrontação dessa gama variada de "fios narrativos" [narrative threads], o ato de testemunhar conformou uma intricada "gramática da dor" [grammar of pain] (Ross 2003:1); tecido fiado não apenas por meio das palavras ditas e escritas, mas pelo tênue ajuste entre dizeres, gestos, silêncios e aquilo que se é capaz ou se está apto a escutar (Ross 2003:49). Nos termos da autora, "eventos passados" e a "conjuração do presente" são entremeados às "cadências da linguagem e do silêncio" por aquilo que emerge como violação e por todas aquelas experiências que, elididas, tornaram-se inaudíveis em tais Comissões (Ross 2003:5).

Visto por tais escrutínios, o caso envolvendo Yvonne Khutwane é central para os argumentos da autora. Descrita pela Comissão como a primeira mulher a testemunhar sobre uma violência sexual infringida a um corpo feminino durante o apartheid, Yvonne Khutwane foi também a única ativista de Zwelethemba - município próximo à cidade do Cabo - a oferecer testemunho. Seu depoimento, primeiramente colhido por escrito, foi depois prestado em audiência pública e, por fim, registrado em pelo menos quatro passagens dos relatórios oficiais. Além dessas aparições, trechos de seu testemunho foram divulgados pela mídia impressa de Worcester e sua história ganhou repercussão em sua comunidade local, tendo resultado em inúmeras intervenções impostas diretamente à sua vida íntima por líderes religiosos e psicólogos. Segundo Fiona Ross, Khutwane procurou a Comissão 
no intuito de testemunhar sobre a tortura, os incêndios criminosos à sua residência, as falsas acusações de ser uma delatora [snitch] e seu consequente isolamento em sua comunidade. Contudo, o que para ela era considerado consequência direta do apartheid em sua vida foi perdendo terreno em face do relato do abuso sexual, extraído de Khutwane mediante as intervenções sistemáticas empreendidas pela psicóloga Pumla Gobodo-Madikizela. ${ }^{4}$ É da contraposição e do rastreamento das continuidades e das descontinuidades desses diferentes fios narrativos que o silêncio ganha lugar na etnografia de Ross.

Daí a excelente imagem tecida pela autora com vistas a deslindar as inúmeras e por vezes perversas modulações impostas entre o que é dito, o que é silenciado e a escuta como uma aptidão. Inspirada pela árida e realista descrição da orelha e do aparelho auditivo, formulada pela romancista Jeannete Winterson, Ross afirma que "a caracterização da orelha física age como um contrapeso" às "dificuldades de ouvir e atender às histórias de dor e perda" relatadas perante à Comissão (Ross 2003:28). Ou seja, ainda que a Comissão estivesse com seus ouvidos ali presentes, a casa incendiada ou as falsas acusações que acabaram por manchar a confiabilidade de Yvonne como uma ativista engajada na luta contra o apartheid restaram inaudíveis nesses aparatos e, por este motivo, silenciadas na busca por reparação.

Por fim, Haunting the Korean Diaspora propõe pensar os silêncios legados no seio familiar em razão de traumas vividos no passado e as "assombrações transgeracionais" [transgenerational haunting] que os perpetuam no presente (Cho 2008:6). Misturando diferentes métodos de pesquisa, como a autoetnografia, a psicanálise e os estudos da performance, Grace Cho se debruça sobre a história de mulheres coreanas que imigraram para os Estados Unidos ao final da Guerra da Coreia (1950-1953) após se casarem com soldados norte-americanos. Forçadas a prestar serviços sexuais às tropas estrangeiras durante o conflito, elas ficaram conhecidas sob a alcunha pejorativa de yanggongju - "princesas do ocidente" - não regressando jamais ao seu lugar de origem. O foco da autora não recai, entretanto, sobre as experiências de tais mulheres, no sentido em geral conferido a esse conceito (Scott 1998). Justamente por não apresentarem discursos coesos sobre seus traumas, essas mulheres escapam à análise sociológica convencional (empreendida tanto em termos quantitativos quanto qualitativos), permanecendo num quase anonimato que é, ele próprio, fruto do silenciamento ao qual se submeteram. Como resultado, a narrativa de Cho move-se num terreno instável onde o distanciamento metodológico dá lugar a um mergulho subjetivo, mas não menos elucidativo, sobre o problema do trauma. 
Filha de uma dessas "noivas de guerra" [war brides], Grace Cho inicia o livro situando-se no centro de sua própria narrativa. O desejo de contar "como o silêncio veio a definir a trama de meu cotidiano" (Cho 2008:1) servirá de mote a partir do qual a figura fantasmal da yanggongju e a presença inarticulada de sua mãe fundem-se nas mesmas intenções analíticas. Deste ponto de vista, o recurso às memórias de infância toma uma proporção indissimulável na medida em que permite à autora perseguir os fantasmas de sua própria família. Encarnando a metáfora de uma nação violada, mulheres como a mãe de Grace Cho foram obrigadas a conviver com o sentimento de desonra de suas famílias de origem, além do rechaço por parte da sociedade que supostamente as acolheu.

Oriundo da psicanálise, o termo "assombração transgeracional" desloca a ideia de que a recusa em falar sobre um trauma inibiria o seu reaparecimento, eventualmente levando-o à extinção; ao contrário, Grace Cho argumentará que o silêncio instaura um "hiato" [gap] nas histórias familiares, fazendo com que o trauma "adquira vida própria" (Cho 2008:6) e espraie-se no dia a dia na qualidade de uma "assombração" insidiosa e muitas vezes involuntária. ${ }^{5}$ Talvez por isso a autora evite preencher os "hiatos" com nomes que possam suprimir os efeitos do trauma e, em vez disso, procure cercar-se deles na tentativa de descobrir "o que se pode aprender ouvindo o silêncio" (Cho 2008:17).

\section{Caminhos para o silêncio}

Interessados em narrativas configuradas em contextos de violência, os três trabalhos destacam-se pela maneira astuta como tratam a questão do silêncio que, longe de ser o "resto" vaticinado por Hamlet, compõe a trama de significados que emerge desses distintos universos de pesquisa. Para Veena Das, o que se apresenta na fala de Manjit como "o não narrativo" sobre a violência da Partição "é indizível nas formas da vida cotidiana" (Das 1999:39), e a lembrança dessa violência é comparada a um veneno que deve ser administrado internamente em vez de expelido. Tal "conhecimento venenoso" ensejaria, assim, essas "não narrativas". Envolvidas em um código silente, elas não devem ser entendidas como incapacidade ou impossibilidade de verbalizar a dor, por vezes tida como "irrepresentável"; o silêncio que as engendra é, ele próprio, a condição de possibilidade da elaboração de uma experiência que, por sua intensidade, explode os limites do vivido. Nesse sentido, não se trata de suprimir memórias ou mesmo enterrá-las, mas de forjar um tipo de "linguagem interna" [inner language] que permita reconstruir um mundo vivível (Das 2007:11). 
No caso de Fiona Ross, uma vez que todo "ato de narrar é produzido por silêncios e rasuras" (Ross 2003:7), silenciar aparece sempre à contraluz daquilo que é dito, não sendo neutro, homogêneo, tampouco uniforme em seus efeitos. Ao não alocar o silêncio no domínio do indizível, a autora está atenta tanto aos lugares de elocução ocupados pelos sujeitos quanto aos modos pelos quais narrar a violência, a perda e o sofrimento estão entranhados por aquilo que se escolhe internamente não falar. Ou, ainda, por aquilo que se profere mediante outros expedientes narrativos que não aqueles canonizados pela forma-testemunho. Das decisões ativas empreendidas por aqueles que escolheram não testemunhar nas Comissões aos modos pelos quais o testemunho de Yvonne Khutwane foi elidido, condensado e cristalizado, eleva-se, portanto, a aposta de Ross: narrativas e modos de narrar não são inertes ou acabados, nem "descansam" depois que são proferidos. Como sugere a autora, "as palavras faladas e os silêncios esculpem-se mutuamente e podem assumir uma espécie de tangibilidade", uma vida cujos rastros lhe são próprios (Ross 2003:101).

Para Grace Cho, a prestação de serviços sexuais das yanggongju aos soldados norte-americanos durante a Guerra da Coreia, somada ao isolamento cultural e linguístico resultante da diáspora dessas mulheres, impediu-as de elaborar a vivência traumática da domesticação da violência, infligida a um só tempo a seus corpos e à sua nação. No caso da mãe da autora, que imigrou para os Estados Unidos desposada pelo inimigo provavelmente ainda na infância ${ }^{6}$ é possível que o silêncio em relação ao passado, tão presente no cotidiano familiar, fosse uma escolha deliberada. De qualquer forma, ele acabou por converter-se no meio de propagação dos fantasmas que viriam a assombrar as gerações futuras, e o trauma da violência sofrida, por sua vez, de não narrado passa a não narrável.

Ao tomarem o silêncio não como obstáculo, mas como parte fulcral de suas investigações, as três obras são exemplares em mostrar que o silêncio tem contornos outros que não apenas ausência. Ele seria "aquilo que parece conduzir nosso olhar, como um interlocutor que insiste que prestemos atenção na bruxaria ou no gado, tumultuando e alterando nosso roteiro inicial de pesquisa", como argutamente formulou Vianna (2014:47). Mais do que mero não dito, o silêncio é também ação: há intencionalidade no gesto de calar. Foucault (1988), ao dissertar sobre a teia discursiva que, durante o século XIX, não cansou de fazer falar o "sexo", afirma o quão improdutivo parece ser "fazer uma divisão binária entre o que se diz e o que não se diz" ou em acreditar que exista "um só" silêncio. Lançando suas apostas à multiplicidade de silêncios e a eles como "parte[s] integrante[s] das estratégias que apoiam e atravessam os discursos", o autor nos incita 
a olhar para "as diferentes maneiras de não dizer"; aos finos mecanismos pelos quais se distribuem aqueles que "podem e os que não podem falar, que tipo de discurso é autorizado ou que forma de discrição é exigida a uns e outros" (Foucault 1988:33-34).

É a esta miríade de caminhos para e atenta ao silêncio que nosso ensaio bibliográfico busca se somar. Se o silêncio se faz notar na abstenção da fala ou na ausência de som, por diversas vezes o "não narrável" se metamorfoseia em outras modalidades: um debulhar em lágrimas, um riso nervoso, uma fala desconexa ou a recusa deliberada em expressar-se. Pode ser uma pausa, um suspiro, a respiração profunda ou ofegante. Por vezes, um olhar perdido ou desviado, um cerrar de pálpebras. Entendido em seu caráter produtivo, portanto, o ato de silenciar comunica aquilo que se esconde, aquilo que se evita fazer, aquilo que não se vê, não se diz, não se escuta e não pode ser preenchido, além de modelar mutuamente o que se verbaliza.

Tudo aquilo que é ativamente silenciado por Manjit exige que Veena Das lance seu olhar tanto para a Partição como evento crítico quanto para as pequenas violências que, ordinárias, atuam na vida cotidiana de sua interlocutora. Por expedientes distintos, a verborragia colocada em ação por Yvonne durante seu depoimento à Comissão interpela Fiona Ross. Ela se vê obrigada a se enredar por muitos fios narrativos que, desfiados, cortados ou tecidos, dão carne à vida de Khutwane como - apenas e sobretudo - uma vítima de abuso sexual durante o apartheid. E é do olhar silente de sua mãe para a parede, em resposta às perguntas da filha sobre seu passado, que Grace Cho cunha a noção de fantasmagoria, a partir da qual uma história concomitantemente nacional e íntima pode ser recontada. Sem dúvida, as palavras e a sua falta eram metaforicamente labaredas de fogo [ghost flames] que brotavam da terra extenuada pela guerra (Cho 2008:82).

Em suma, mais do que teorizações filosóficas acerca do silêncio, Veena Das, Fiona Ross e Grace Cho figuram como importantes inspirações àqueles que estão implicados etnograficamente em profícuas encruzilhadas entre o dito e o não dito. Pesquisadores que assim como nós se encontram entretecidos nos mesmos dilemas com que Hamlet enredou Horácio ao fazê-lo se ater somente àquilo que, precisamente por ser ungido pelo poder das palavras, figurava como crucial e digno de ser recontado. Manjit, Ivone e a mãe de Cho parecem exigir mais não só de suas interlocutoras acadêmicas, mas também de nós, ávidos leitores. Sem dúvida, as cenas etnográficas que se desenham dessas relações nos encorajam, inclusive, a desmantelar a máxima hamletiana. Quiçá fosse importante a Horácio estar atento tanto às palavras ditas por Hamlet quanto a tudo aquilo que restava, sem pompa ou circunstância, em silêncio. 
Recebido em: 22 de fevereiro de 2019

Aprovado em: 25 de outubro de 2019

Larissa Nadai é pós-doutoranda do Programa de Pós-Graduação em Antropologia Social da Universidade de São Paulo (USP), com bolsa da Fundação de Amparo à Pesquisa do Estado de São Paulo (Fapesp), 2018/26728-4. É doutora em Ciências Sociais e mestre em Antropologia Social pela Universidade Estadual de Campinas (Unicamp). Também atua como pesquisadora do Núcleo de Etno-História da USP e é pesquisadora colaboradora do Ateliê de Produção Simbólica e Arte (APSA) da Unicamp. Seus principais campos de atuação e pesquisa são gênero, sexualidade, práticas estatais e poder político, ordenamentos jurídicos e processos de documentação e arquivamento.

https://orcid.org/0000-0003-0362-5420

E-mail: lari.antropologias@gmail.com

Rafael do Nascimento Cesar é doutorando em Antropologia Social pela Unicamp, onde também obteve o título de mestre em 2015. Realizou recentemente um estágio de pesquisa na Universidade de Illinois, nos Estados Unidos, financiado pela Fapesp. Seus temas de pesquisa são música popular brasileira, jazz, relações raciais e de gênero e tem publicações em diversos periódicos acadêmicos, como nas revistas Tempo Social, Mana, Sociologia \& Antropologia e Cadernos Pagu. https://orcid.org/0000-0003-4901-246X

E-mail: rafaelnascimentocesar1@gmail.com

Cilmara Veiga é doutoranda CNPq (Conselho Nacional de Desenvolvimento Científico e Tecnológico) do Programa de Pós-Graduação em Ciências Sociais (PPGCS) da Universidade Estadual de Campinas (Unicamp) e mestre em Antropologia Social pela mesma instituição. Suas principais áreas e temas de atuação e pesquisa são gênero, sexualidade, violência, crimes seriais e práticas estatais e de documentação.

https://orcid.org/0000-0001-6257-7647

E-mail: cilveiga@gmail.com 


\section{Notas}

1 Tanto pela inegável complexidade de tais obras quanto pelos limites propostos para este ensaio, demos especial atenção a alguns dos capítulos escritos por Veena Das, Fiona Ross e Grace Cho. No caso de Life and Words, centramos nossa análise nos primeiros cinco capítulos, com enfoque nos relatos etnográficos relativos à história de vida de Manjit. À contraluz deste exemplo, os capítulos sobre a Assembleia Constituinte e o processo de consolidação da Índia enquanto Estado-nação ganham importantes contornos em nossa argumentação. Quanto a Bearing Witness, os quatro primeiros capítulos são centrais, sobretudo os fios narrativos que emergem do testemunho prestado por Yvonne Khutwane à Comissão de Worcester, na África do Sul. Finalmente, em Haunting the Korean Diaspora orientamos nossa atenção à introdução e aos dois primeiros capítulos. Nossa escolha lança luz em alguns expedientes etnográficos empreendidos pela autora: as assombrações intergeracionais, a autoetnografia e os hiatos que conformam o que a autora denomina de uma escrita traumatizada.

2 É importante destacar que as três obras foram lidas conjuntamente por nós durante as reuniões coordenadas por Maria Filomena Gregori com seu grupo de alunos. Fruto de interesse de inúmeros dos trabalhos realizados sob sua orientação, a leitura dessas autoras desdobra questões cadentes aos participantes do grupo, tais como violência, sofrimento, gênero, sexualidade e dispositivos de gestão e controle dos corpos. A reunião dessas autoras, todavia, remonta ainda a outros circuitos intelectuais, em especial aqueles levados a cabo pela antropóloga Adriana Vianna e seus orientandos, no Museu Nacional, Rio de Janeiro. Neste caso, ao tratarem de temas como sofrimento, violência, gênero, Estado e política de memória e reparação, seus trabalhos têm demonstrado a proficuidade de correlacionar as mencionadas obras, com ênfase nas dimensões éticas, estéticas e narrativas em que sofrimento, práticas de pranteamento e violência se entrelaçam.

3 Ainda que as autoras sejam profundamente originais em suas análises e proposições, a questão dos silêncios e das narrativas para a qual voltamos nosso olhar neste ensaio foi explorada anteriormente - a partir de outras matizes analíticas e teóricas - por importantes autores, especialmente no contexto do entreguerras e do pós-Segunda Guerra Mundial, sendo de extrema relevância e referência para distintos campos de reflexão, como a história, a literatura, a filosofia etc. Para outras perspectivas sobre modos de narrar, silêncio e esquecimento, ver Pollak (1989); para uma análise sobre a intrínseca relação entre narrativa, tempo, memória e historiografia, ver Ricoeur $(1994,2012)$; para uma reflexão sobre as articulações entre narração, experiência e silêncio, ver Benjamin (1994).

4 Como sublinha Ross, o abuso sexual não foi retratado por Yvonne Khutwane no depoimento entregue por ela à Comissão. Durante a audiência, tais injúrias só foram narradas depois que a psicóloga Pumla Gobodo-Madikizela passou a conduzir ativamente o testemunho de Yvonne. Soma-se a tais expedientes o fato de que, nos relatórios da Comissão, tais intervenções foram suprimidas e o testemunho de Khutwane foi registrado como uma narrativa construída sem interferências ou constran- 
gimentos exteriores. Do mesmo modo, as repercussões midiáticas que se seguiram ao depoimento de Yvonne contavam com trechos e passagens comoventes incluídos pela mídia impressa, sem que tivessem sido proferidos pela ativista em seu testemunho. Visto por este ângulo, portanto, o testemunho da ativista satisfazia uma solicitação exterior formulada (estatisticamente) e demandada à Comissão: a necessidade de que violações empreendidas ao corpo físico das mulheres fossem contabilizadas e viessem à tona. Estabelecia-se, assim, uma perversa "estratificação" das experiências definidas, reconhecíveis e atestadas como violência ou violação de direitos humanos.

5 A polissemia do verbo em inglês to haunt permite que o entendamos simultaneamente como "assombrar" e como "perseguir". Por exemplo, na frase "Haunted by ghosts, haunted by memory", no primeiro caso, os fantasmas assombram os vivos; no segundo, a memória persegue o passado e assedia quem o viveu. Esse efeito de sentido, próprio da língua inglesa, é explorado por Grace Cho e convertido em uma premissa analítica na qual "através da perseguição/assombração [haunting] da diáspora coreana um método de ver e falar sobre o trauma é composto de imagens, afetos e vozes dispersas" (Cho 2008:24).

6 Na dedicatória do livro é possível ler "For my mother, 1941-2008", o que nos autoriza a pressupor que se a mãe e o pai de Grace Cho se conheceram ainda durante a guerra, a primeira devia contar entre 10 e 13 anos de idade. 


\section{Referências bibliográficas}

BENJAMIN, Walter. 1994. Magia e técnica, arte e política: ensaios sobre literatura e história da cultura. São Paulo: Brasiliense.

CHO, Grace. 2008. Haunting the Korean Diaspora: shame, secrecy and the Forgotten War. Minneapolis/London: University of Minnesota Press.

DAS, Veena. 1999. "Fronteiras, violência e o trabalho do tempo: alguns temas wittgensteinianos". Revista Brasileira de Ciências Sociais, 14 (40):31-42. . 2007. Life and Words: violence and the descent into the ordinary. Berkeley/Los Angeles: University of California Press.

FOUCAULT, Michel. 1988. A história da sexualidade I: A vontade de saber. Rio de Janeiro: Edições Graal.

MERLEAU-PONTY, Maurice. 2004. O Olho e o Espírito. São Paulo: Cosac e Naify.

POLLAK, Michel. 1989. "Memória, Esquecimento e Silêncio". Revista Estudos Históricos, 2 (1):3-15.

RICOEUR, Paul. 2012. "Entre tempo e narrativa: concordância/discordância". Kriterion: Revista de Filosofia, 53 (125):299-310.

RICOEUR, Paul. 1994. Tempo e Narrativa. Campinas: Papirus.

ROSS, Fiona. 2003. Bearing Witness: women and the Truth and Reconciliation Commission in South Africa. London/Sterling, Virginia: Pluto Press.

SCARRY, Elaine. 1985. The Body in Pain: The Making and Unmaking of the World. New York: Oxford University Press.

SCOTT, Joan W. 1998. "A invisibilidade de experiência". Projeto História Cultura e Trabalho, 16:297-325.

SHAKESPEARE, William. s/d. Hamlet. Porto: Lello \& Irmão Editores.
VIANNA, Adriana de Resende Barreto. 2014. "Etnografando documentos: uma antropóloga em meio a processos judiciais". In: S.R.R. Castilho; A. C. de Souza Lima \& C, C. Teixeira (orgs.), Antropologia das Práticas de Poder: reflexões etnográficas entre burocratas, elites e corporações. Rio de Janeiro: Contra Capa/Faperj. pp. 43-70. 
DE VENENOS, ESCUTAS E

ASSOMBRAÇÕES: CAMINHOS PARA

ETNOGRAFAR O SILÊNCIO

\section{Resumo}

Este ensaio bibliográfico busca lançar luz sobre o caráter produtivo do ato de silenciar, bem como daquilo que se torna dizível por meio de outros expedientes que não a palavra proferida - olhares, gestos, pausas. Para tanto, propomos a leitura articulada de três obras: Life and Words, de Veena Das; Bearing Witness, de Fiona Ross; e Haunting the Korean Diaspora, de Grace Cho. Nossa escolha diz respeito à qualidade expressa pelas três etnografias em elevar o silêncio a um patamar heurístico e, com isso, colocar sob rasura as representações do silêncio como reino do incognoscível, da falta ou da ausência de linguagem. Ao recompor tais imagens e figurações, temos por intuito destacar outras modalidades e caminhos para etnografar o silêncio que sirvam de inspiração a pesquisas cujos campos empíricos exijam atenção tanto às palavras ditas quanto aos meandros pelos quais se escolhe ativamente calar. Palavras-chave: Silêncio; Violência; Trauma; Gênero; Etnografia.
DE VENENOS, ESCUCHAS Y

FANTASMAGORÍA: LOS CAMINOS

DEL HACER ETNOGRÁFICO DEL SILENCIO

\section{Resumen}

Este ensayo bibliográfico pretende arrojar luz sobre el carácter productivo del acto de silenciar, así como sobre lo que se puede tornar decible por otros medios que no la palabra hablada: miradas, gestos, pausas. Para ello, proponemos la lectura articulada de tres obras: Life and Words, de Veena Das; Bearing Witness, de Fiona Ross; y Haunting the Korean Diaspora, por Grace Cho. Nuestra elección tiene que ver con la calidad expresada por estas tres etnografías al elevar el silencio a un nivel heurístico y, por lo tanto, borrar las representaciones del silencio como un reino de lo desconocido, de la falta o de la ausencia del lenguaje. $\mathrm{Al}$ recomponer tales imágenes y figuraciones, nuestro objetivo es resaltar otras modalidades y caminos del hacer etnográfico del silencio que podrán inspirar a las investigaciones cuyos campos empíricos demandan atención tanto a las palabras habladas como a los meandros por los cuales se elige activamente el silencio.

Palabras clave: Silencio; Violencia; Trauma; Género; Etnografia. 


\title{
OF POISONS, LISTENING AND \\ HAUNTING: PATHS TOWARDS AN \\ ETHNOGRAPHY OF SILENCE
}

\begin{abstract}
This bibliographic essay seeks to shed light on the productive character of the act of silencing, as well as of what can be said through expedients other than the spoken word - looks, gestures, pauses. Therefore, we propose the joint reading of three works: Life and Words, by Veena Das; Bearing Witness, by Fiona Ross; and Haunting the Korean Diaspora, by Grace Cho. Our choice concerns the quality expressed by the three ethnographies in elevating silence to a heuristic level and, thereby, contradicting the representations of silence as the realm of the unknowable, the lack or absence of language. By recomposing these images and figurations, we aim to highlight other modalities and paths towards an ethnography of silence that serves as inspiration for researchers whose empirical fields demand attention both to the words spoken, and the intricacies through which one actively chooses to keep silent.
\end{abstract}

Key words: Silence; Violence; Trauma; Gender; Ethnography. 